\title{
A decision support system for sustainable groundwater management. Case study: Gnangara sustainability strategy - Western Australia
}

\author{
A. Elmahdi ${ }^{1}$ \& D. McFarlane ${ }^{2}$ \\ ${ }^{1}$ CSIRO Land and Water, Adelaide, Australia \\ ${ }^{2}$ CSIRO Water for a Healthy Country Flagship, Perth, Australia
}

\begin{abstract}
The Gnangara Sustainability Strategy is a cross-government initiative that aims to ensure there is sufficient groundwater in the Gnangara Mound for drinking and commercial use, and to meet existing and future environmental needs. The Gnangara Groundwater System (GGS) is a large aquifer situated in the southwest region of Western Australia. Historically, the GGS has been considered to be an infinite reservoir for water, but this impression has quickly shifted following the realization that $45 \mathrm{GL}$ of water has been lost per annum since the late 1990s. The main causes for this loss are lower rainfall since 1975; land uses that reduce recharge; and increased water extraction. As a result, many significant environmental features, especially wetlands, are declining in health and value.

The GGS faces increasing demands for its water from several key users within the public water supply, environmental and agricultural sectors. However, declining water levels related to climate change, demand urgent prioritisation of a set of inter-sectoral and inter-temporal land use planning and water abstraction rules that would maximize societal welfare while ensuring the sustainability of this crucial water source and its dependant ecosystems. The sustainable management of the GGS is a major problem for water and environmental managers because of the complexity and interconnectedness of the system. Innovative modelling approaches should be employed to assist in better decision making by modelling the feedback loops inherent in the system and analysing the impact of alternative land use and water policy scenarios.
\end{abstract}

This paper details a systems approach to developing an integrated decision 
support system (DSS) to enable these complex land and water use options to be evaluated in economic, social and environmental dimensions. A total of 29 subareas were identified (based on flow direction, allocation and similar land-use) and modelled under six geographical zones. Each sub-area was modelled by the main interconnected six modules and quantitative indicators (environment, economic and social) values were calculated. Seven scenarios were tested: i) business as usual (BAU); ii) maximizing recharge; iii) maximizing biodiversity; iv) maximizing short term economic gains; v) a Mixed use Post-Pine; vi) maximizing food security, and; vii) zero abstraction for public water supply by 2013. Preliminary results from the DSS are presented with an emphasis on understanding the tradeoffs between these scenarios. Most scenarios lead to a declining water table in the GGS, which by 2030 is up to 8 meters lower from the current levels. This would lead to a significant loss of biodiversity and wetlands. Changing and reallocating land use (e.g. grassland as post pine landuse) could improve recharge but this cannot reverse the overall trend of falling levels because climate change is pervasive.

Keywords: DSS, groundwater, sustainable management, scenario analysis, integrated modelling.

\section{Introduction}

Water problems throughout the world can be seen as an issue of management, not a crisis of water shortage. Equitable allocation of groundwater resources is a growing challenge due to the increasing demand for water and the competing values placed on its use. Sustainable management of water resources comes with compromises and trade-offs of the other sub-systems (environment, economic and social) and almost ignores other stakeholders' objectives and benefits. Groundwater is a vital resource in Australian. Increased demand for water resulting from rapid economic development accompanied by poor climatic conditions (e.g. low rainfall levels) has induced an increased reliance on groundwater harvesting to sustain demands. The management of the groundwater system is a major problem for water and environmental managers.

A major challenge is to anticipate future water demands and supplies in a drying climate to accommodate the needs. In Australia, this challenge is very clear in Perth-Western Australia- Australia's most rapidly growing city as the urban area extends onto the recharge area of the unconfined aquifer. The case study is the Gnangara Mound groundwater system, the most valuable and largest single source of water in Western Australia (WA). Gnangara Moundgroundwater system currently supplies about $60 \%$ of Perth's potable water supply and more than $85 \%$ of all water demand (e.g. irrigation of parks and gardens, industry and peri-urban horticulture). Land use changes, climate change and many other factors have resulted in extreme recharge and discharge changes in the Gnangara Mound groundwater system, and the situation is no longer economically or socio-economically feasible. Raising awareness of sustainable groundwater is a crucial step [7]. 
Sustainable water management is necessary to match all stakeholders/agencies' interests and profits. Sustainability has become a major driving force for better water management systems [6]. The Gnangara groundwater system is very complex and interconnected system, posing significant challenges in managing it sustainably. Therefore, there is a need to explore new tools to represent the complex relationships found in Groundwater system. One of those promising options is SD, a feedback-based, object-oriented approach. Although not a novel approach, system dynamics offers a new way of modelling the future dynamics of complex systems in a transparent way. According to [11], system dynamics is based on the theory of system structure and on a set of tools for representing complex systems and analysing their dynamic behaviour. The most important feature of SD is to elucidate the endogenous structure of the studied system, to see how the system components relate to one another and to experiment with changing relations when different decisions are included.

Moreover, the inherent flexibility and transparency of SD is particularly helpful for the development of Decision Support System (DSS)/models for complex water systems with subjective variables and parameters. This allows the application of hierarchical decomposition in DSS development and an accrued transparency in its development. It also raises the possibility of practitioners' involvement in the DSS development, increasing their confidence in its operation and outputs [13]. Compared with conventional simulations such as hydrological modelling or optimisation models, the system dynamics approach when linked with physical models (e.g. Modflow) gives a better outcome in simulating how different changes in basic elements alters the dynamics of the system [1].

\section{Case study: Gnangara Mound groundwater system}

The Gnangara Mound is the largest source of groundwater for Perth (pop. 1.5 million), the capital city of WA. This groundwater system extends under the Swan Coastal Plain for approximately $2200 \mathrm{~km}^{2}$ north of the Swan River. Land use in the north is dominated by state-owned pine forests and natural bushland. South of the mound, the land is mainly urbanised with horticulture prominent in the Wanneroo, Gingin, and upper and middle Swan areas. Figure 1 shows simplified types of common land use on the Gnangara Mound. Groundwater from the Gnangara Mound currently supplies about $60 \%$ of Perth's potable water supply and more than $85 \%$ of all water demand (e.g. irrigation of parks and gardens, industry and peri-urban horticulture).

The Gnangara Sustainability Strategy (GSS) is a cross-government initiative working on an action plan for sustainable use of water and protection of the environment. Seven government agencies - the WA Department of Water, the Department of Agriculture and Food WA, the WA Department of Environment and Conservation, the WA Department for Planning and Infrastructure, the Forest Products Commission WA, the WA Water Corporation and the Commonwealth Scientific and Industrial Research Organisation (CSIRO) - have joined forces to form a taskforce group (TFG) to implement the GSS. The aim of 


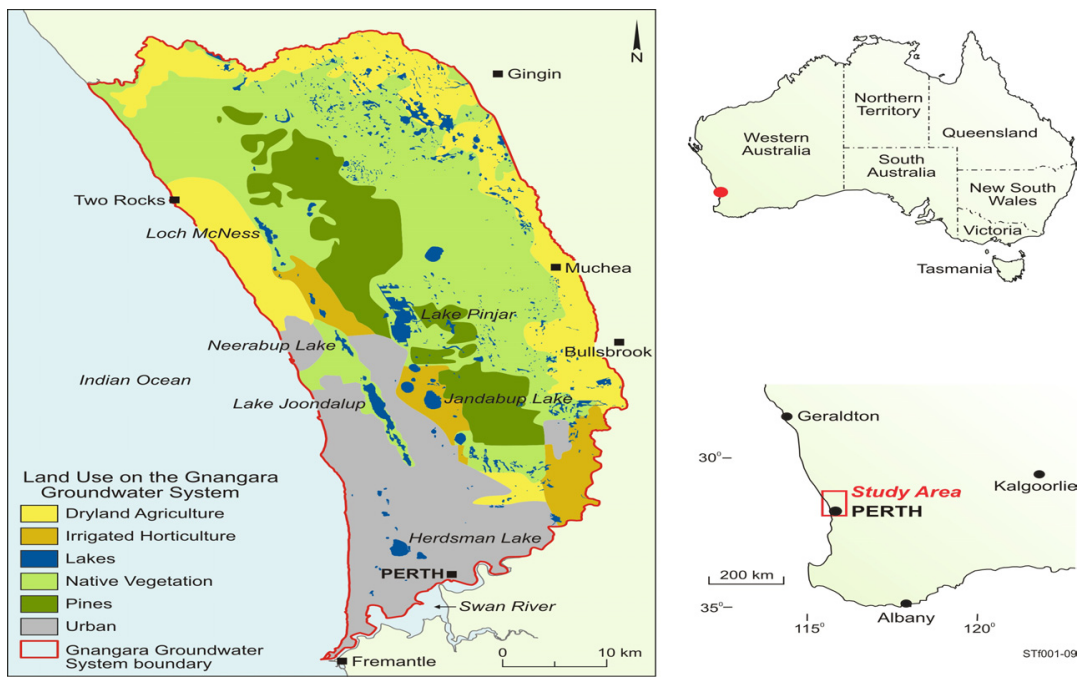

Figure 1: $\quad$ Gnangara Mound area and common land use type.

the GSS is to ensure there is sufficient groundwater in the Gnangara Mound for drinking and commercial use, and to protect the environment - now and in the future.

\subsection{Water resource management issues}

The Gnangara Mound is a large unconfined surface aquifer and in many locations the watertable is very close to the surface. As a result, many of the area's significant environmental features are dependent on accessing the watertable for their survival. Demand for water is increasing rapidly as the state develops and Perth's population increases. Pressure on the mound is reaching critical levels. Extraction from the Mound is exceeding recharge rates with a consequent decrease in the groundwater levels. Total water use from the mound is currently $336 \mathrm{GL} / y e a r$. Mound groundwater levels have declined progressively since the early 1970s, especially over the last six years. This decline represents a total loss of about 500 GL of water from the mound's superficial aquifer since 1979 (see Figure 2).

Water levels are being impacted by climate change more than many others aquifers in the world [15], and this is expected to become more severe (e.g. downscaling of general circulation models as predicted by [3]). In the last 30 years rainfall declined by $9 \%$ below the long-term average, in the last 10 years the rainfall declined by $12 \%$. However the rainfall declined by $15 \%$ below the long-term average in the last 6 years.

Groundwater levels are declining due to the combined effects of low rainfall, reduced recharge; pine maturation and increasing abstract (see Figure 3). However, climate is considered the dominant influence on groundwater levels. The relative contribution of these factors varies over different areas of the 
mound. The major cause for the groundwater level decline is due to reduction in recharge, which accounts for $70 \%$ (i.e. $38 \%$ reduction in recharge under pine areas plus $32 \%$ reduction in recharge due to climate). Increased abstraction from the superficial aquifers accounts for $23 \%$ of the decline and increase in confined abstraction accounts for only $7 \%$. This makes a 'one solution fits all' strategy impossible given the interdependence of the components, a more considered and process informed strategy is much more likely to be successful. Management of the Gnangara Mound groundwater system therefore requires a tailored approach.

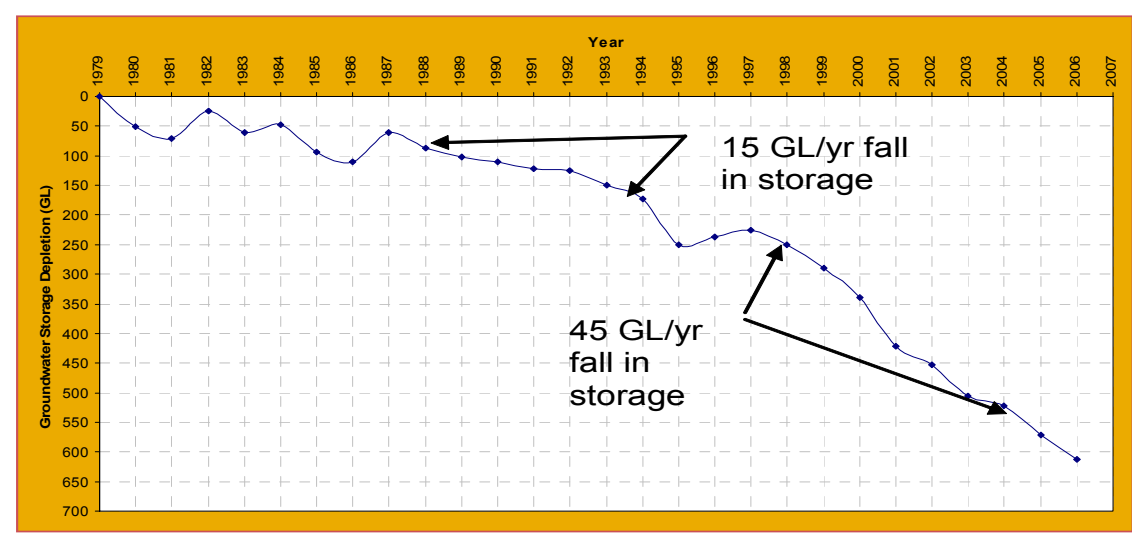

Figure 2: $\quad$ Groundwater storage depletion, 1979-2006.

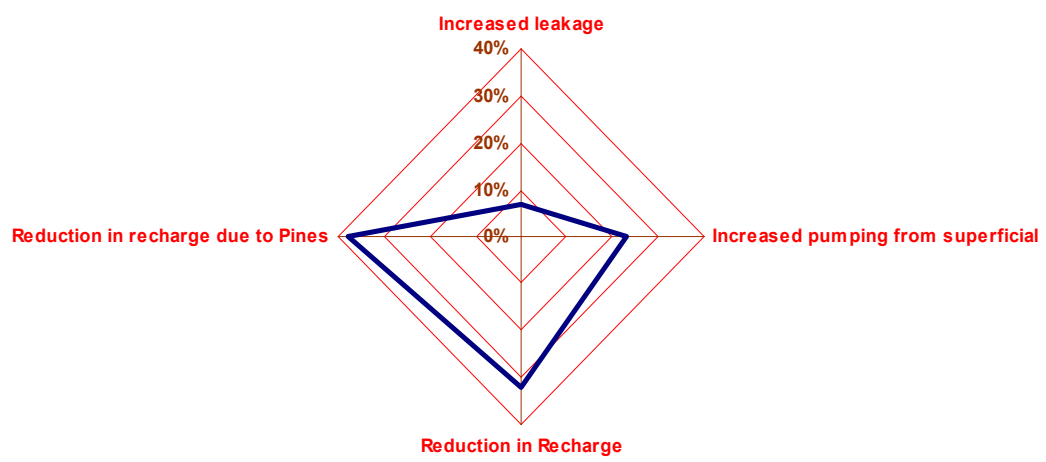

Figure 3: Relative contribution of Gnangara Mound groundwater decline factors.

A major challenge is to anticipate future water demand and supply in a drying climate to accommodate the needs of Perth, Australia's most rapidly growing city $(2.7 \%$ growth rate). The management of the GSS is a major problem for water and environmental managers. The Gnangara groundwater system is very complex and interconnected, posing significant challenges in managing it sustainably. The main issues for resource and water managers are deciding how 
to return the Gnangara groundwater system to a condition of sustainability and how to control the system in a changing climatic regime, taking into account the triple bottom line measures. The triple bottom line values of the groundwater resources need to be better understood and maintained for present and future generations, which requires a tailored systematic approach. To better understand the trade-offs between the triple bottom line and the groundwater system, it is imperative to use innovative modelling approaches. They can improve decisionmaking by modelling the feedback loops inherent in the system and analysing the impact of alternative land use and water policy scenarios (recommended by the TFG at the local-area level). These scenarios include future land use changes, new water allocations, post-pine land use options, establishing groundwater dependent ecosystem (GDE) requirements and bush-burning regimes [4].

\section{The need of the DSS}

In the Gnangara Mound case study, application of the eight steps of the Integrated Multi-agency framework [5] clearly demonstrated the need for a DSS tool to facilitate the process and to communicate the analysis with the community, researchers, stakeholders and water managers. There is a clear tradeoff between the three systems (environmental, social, and economical), so they must be considered as sub-systems. Any maximizations or minimizations of a sub-system objective that does not consider the impacts on the others - although it may appear viable and worthwhile in the limited perspective in which it is considered - may severely damage the overall system (as it has done so far).

In order to comply with the multi-agency framework, there is need to pull together a structured but easy-to-understand platform (i.e. DSS) that addresses different key aspects, such as hydrological, hydraulic, environmental, socioeconomic, finance-economic, institutional-legislative and political-strategic factors. This necessitates simultaneous accounting of many different and noncommensurable pieces of information. It is hugely difficult to perform this without a suitable computer-based tool. It must be noted that the belief that classic optimisation can really solve water resource planning problems, as it was advocated a few years ago, has ended. The simulation paradigm is now considered to be the best approach because simulation models can be more representative of reality and many of the decision variables are not under full control of the stakeholders. If the optimisation paradigm can be used, decisions would be assumed on behalf of other stakeholders. Therefore, optimisation will lead to isolation of the other stakeholders in the water resources planning process, rather than their involvement. Furthermore, dynamic simulation is much more transparent compared to optimisation techniques, which allows the user to understand the interaction and relationships among the different variables, especially the variables related to people. Apart from the difficulty of merging data and pieces of information of a diverse nature (often qualitative and incomplete) two other reasons prevail. The first is the need to comply with vast numbers of rules and regulations that are related to water resources planning and management but often are not provided in an integrated, harmonised and rational 
framework. The second reason is the increasing claim for community participation in decision-making processes.

In summary, our view is that the most fruitful approach is to use computerbased tools (DSS) to predict and assess the effects of any actions by performing an integrated analysis of environmental and socio-economic aspects. This forecasting exercise may rely on a broad set of tools ranging from expert systems, expert-based value functions and empirical equations to complex mathematical models. All or most of these tools can be integrated into one computer-based tool to facilitate and support the multi-agency framework and trade-offs analysis. In addition, the DSS assists the process of communicating the results with stakeholders, government and the community.

\subsection{DSS criteria}

DSS criteria have developed and recommended by the task force group. Theses criteria consider the DSS potential use, development and future update. These criteria are summarized as follow:

- The DSS should be able to assess land and water management options to provide quantitative assessment- (with acceptable technical level)

- It can address several scenarios (climate, land uses, land management, water allocations)

- It can incorporate available economic, social and environmental data and values

- It should be able to communicate scenarios (climatic/water and land) to managers and informed community members

- Spatially distributed information can be included (but not dynamically linked to GIS at this stage); and not highly lumped

- It should be able to incorporate PRAMS (regional groundwater model) / Local Area Model groundwater data but not be dynamically linked (at this stage)

- It should be able to assess different scenarios using different time horizon (2110, 2020, 2030 and 2060) with more precision for 2005 to 2030 likely

- It should be able to include Monthly time-step (to align with climate, PRAMS, groundwater monitoring, seasonal water use)

- Structure able to be adapted to incorporate more detail as required for specific areas/sub-area/ landuse as it becomes available

- Well documented and clear so that it can be used and modified by many workers for building capacity (i.e. not dependent on a single user)

\subsection{DSS modelling approach and structure}

Groundwater management is a complex issue due to the pressure of uncontrolled variables such as climatic conditions. The dynamic character of the main variables and how they affect water use in the future is not properly captured through traditional approaches [8]. Therefore, the complexity of the groundwater system management issue, and the objective of gaining a quantitative understanding, necessitates systems analysis via modelling (i.e. a system 
approach). There are a range of modelling techniques and the choice of technique, as well as the details of model construction, have to be case and objective orientated. The model needs to be a comprehensive, pertinent, operational representation of reality which grasps the essential elements and mechanisms of the system and allows investigation of policy questions. The model must reflect the perspective of stakeholders, if it is to secure acceptance and implementation of the research results.

\subsection{System analysis concept and approach}

Elshorbagy and Ormsbee [9] state that, the system modelling simulation approach relies on understanding the complex interrelationships existing between different objects within a system. This is attained by structuring a model that is able to capture the behaviour of the system. The dynamics of the system could be understood through simulation of the system over time. Describing the system and its boundaries, by using the main variables and its mathematical functions, which represent the physical processes, to generate the model behaviour, is one of the main steps of a system dynamics model. Rumbaugh et al. [10] stated that object-oriented modelling is a way of thinking about problems using models organized around real world concepts. It is a way to organize software as a collection of discrete objects that incorporate both data structure and system behaviour [12]. Data are organized into discrete objects which can be concrete (such as a river gauge or river reach) or conceptual (such as a management or policy decision).

In this study, a system analysis modelling approach is utilized. System analysis modelling offers an efficient approach to most effectively utilize available data and understanding of the processes. The System dynamics tool used in this study to model Gnangara groundwater system under triple bottom line constraints has four basic building blocks; stock, flow, connector and converter. Stocks (levels) are used to represent anything that accumulates (e.g. water storage), flows (rates) represent activities that fill and drain stocks; (e.g. releases or inflows). Connectors (arrows) are used to establish the relationship among variables in the model, the direction of the arrow indicates the dependency relationships. They carry information from one element to another element in the model. Converters transform input into output.

\subsection{DSS concept and design}

Given the complexity and often-contentious nature of resource allocation, success requires a process for the inclusive and transparent sharing of ideas complemented by tools to structure, quantify and visualise the collective understanding and data, providing an informed basis of dialogue, exploration and decision-making $[2,14]$. The need for an integrated multi-agency approach using DSS is a logical approach or way forward to achieve sustainable groundwater management for longer-term planning [4]. By utilising and integrating the expertise of multiple state agencies, we can develop and apply a potential DSS that integrate most of the available information. Without this integration, there is potential for greater conflict between agencies' objectives and actions. 
The futures analysis methodology or process used in this study is shown in figure 4. The key focus of the Gnangara DSS is on the implementation of key identified actions by stakeholders in terms of landuse changes, water allocation and establishing groundwater dependent ecosystem requirements. To be successful it will require significant data and intellectual input from other projects under the GSS so that adaptive management options can be evaluated.

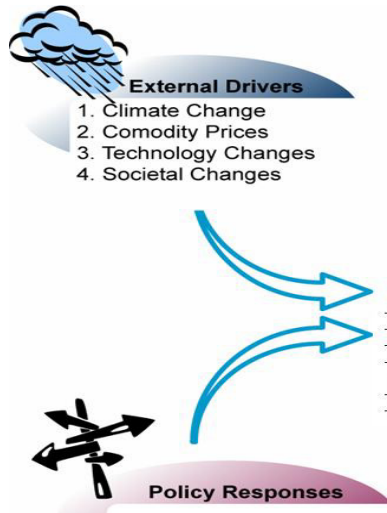

1. Extension

2. Incentives

3. Regulations

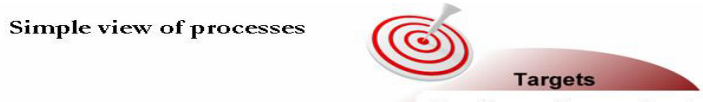

1. Groundwater level

2. Recharge rate

3. Sustainable use

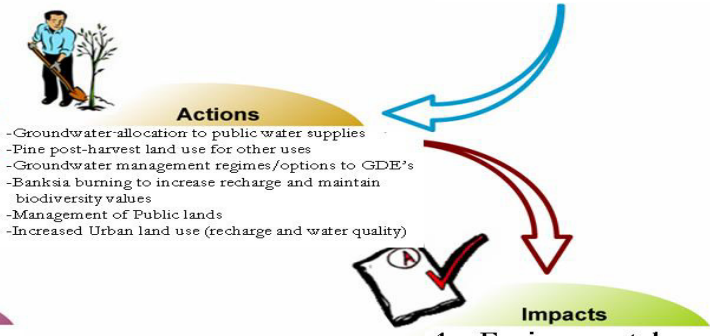

1. Environmental

2. Economic

3. Social

4. Water Level

Figure 4: Conceptual approach.

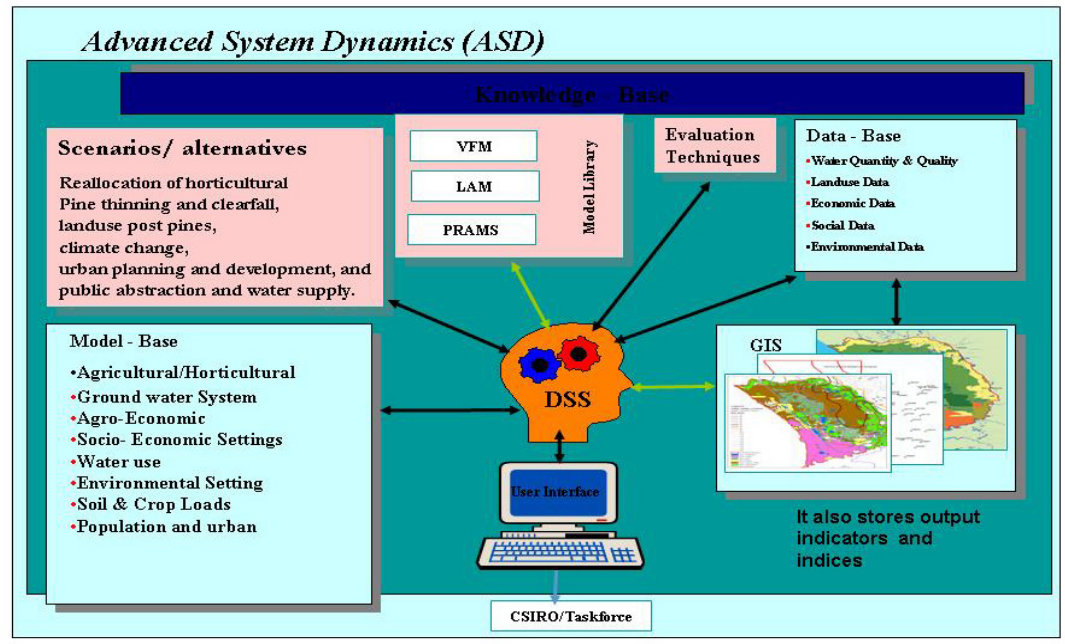

Figure 5: $\quad$ Conceptual DSS linkage.

The framework of the DSS and its linkage to other database and models such as PRAMS (regional groundwater model), LAM (local area model), VFM 
(Vertical flux model), and scenario development is shown in Figure 5. The boundary and the scale of the DSS have been determined by the task force group. A total of 29 sub-areas are modelled under six geographical zones. Each sub-area is modelled by the main interconnected six modules that lead to the quantitative indicators (environment, economic and social) values based on the land use type (see Figure 6). These six modules are tried to represent and mimic the most interdependencies between land use and system components (see figure 7).

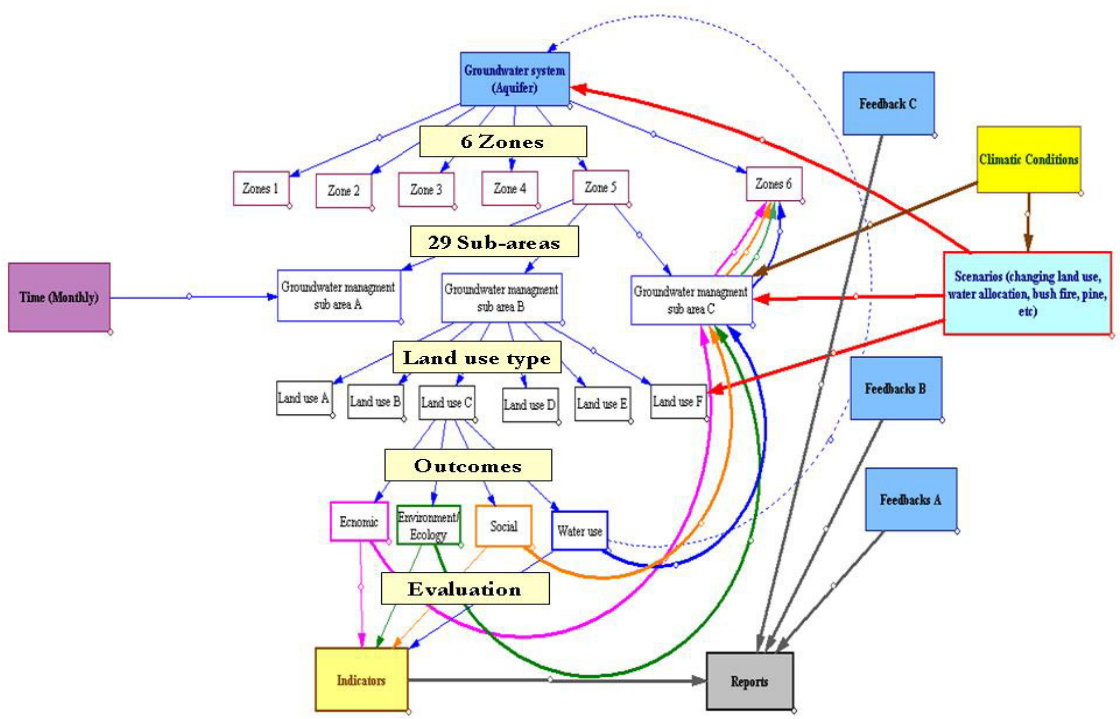

Figure 6: Conceptual design of the DSS.

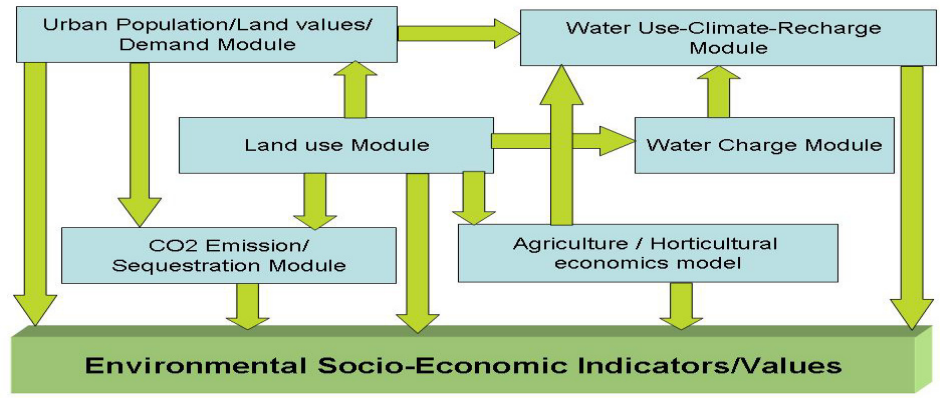

Figure 7: Six main modules linkage.

There are several feedbacks built in the DSS to reflect from low scale/resolution to up scale. All these scales can be tested with different climate condition and other land use scenarios. The developed GSS-DSS is used by TFG to readily set up scenarios in the DSS and analyse their impacts on Gnangara 
groundwater system and its values. This can be done by simple control screens (figure 8); the user can change the DSS assumptions, constants, policy objective. Also, the user can run simulation or even scenario with different time horizon and can do detailed analysis for the results. It can compare several scenarios, see the cause and use tree, and see results as figure or table, and statistical analysis.

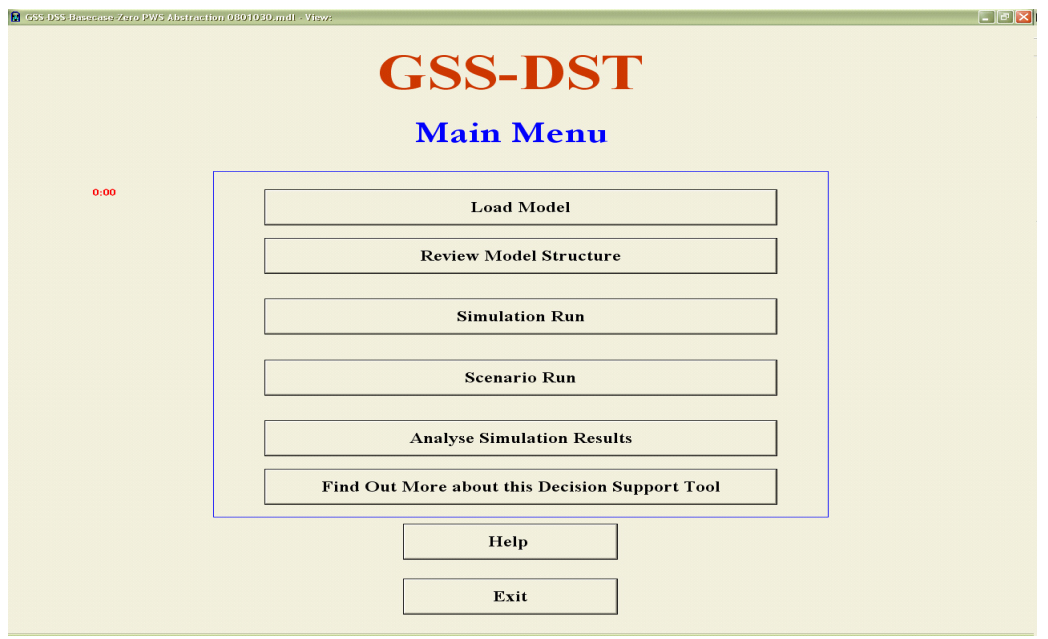

Figure 8: User's control screen.

\section{DSS future scenarios}

In order to design the Gnangara Sustainability Strategy (GSS), several land and water use scenarios have been evaluated in terms of their long term economic, ecological and social impacts. Given the logistical limitations of optimizing over discrete and spatially disparate land and water use options and the challenging task of comparing quantifiable and un-quantifiable benefits across diverse groups; this study identifies seven scenarios that are most likely to reside. Finally, a Mixed use Post-Pine scenario is also considered that highlights the possibility of maximizing returns through judiciously selecting land and water use options away from these boundaries. The seven scenarios (scenario1scenario 7) involve business as usual (BAU), maximizing recharge, maximizing biodiversity, maximizing short term economic gains, a Mixed use Post-Pine, maximizing food security and zero abstraction for public water supply (PWS) by 2013 respectively. The variables considered for the evaluation are the Benefits of the Gnangara Ground Water System (GGS) and the hydrographs depicting average decline in water table under the identified scenarios. Preliminary results indicate that, most scenarios lead to a declining water table on the GGS, which by 2030 is up to 8 meters lower from the current levels (compared to BAU scenario) see figure 9. This would lead to a significant loss of biodiversity and wetlands. The general decline in water trend on the GGS is difficult to stem unless extreme measures are undertaken. These measures could cost society as much as $\$ 285 \mathrm{~B}$ in the long term. 


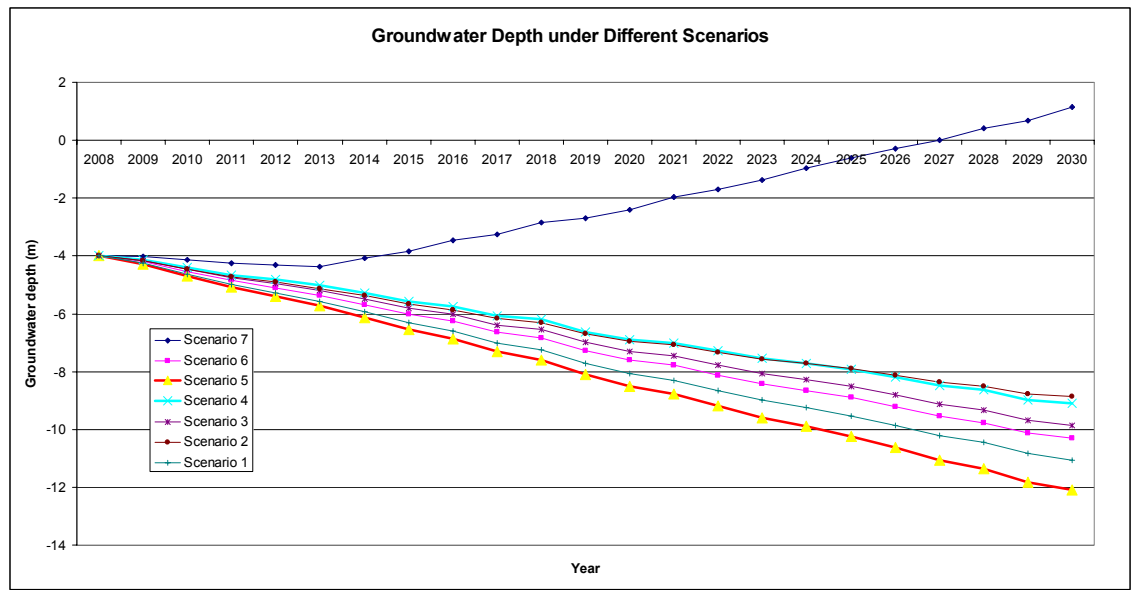

Figure 9: Groundwater depths relative to BAU.

\section{Conclusion}

In Gnangara mound case study, each sub-area has been modelled by six modules interacted to capture the key aspects and Gnangara mound groundwater system behaviour. The Gnangara DSS was developed through the application of a system dynamics approach. The purpose of the DSS is to provide quantitative assessments of priority land and water management options recommended by the Gnangara taskforce at the local area level. These options include future land use changes, new water allocations, post pine land use, options, establishing GDE requirements and bush burning regimes. The DSS is also used to perform economic analyses of the land and water use options. This adds the economic and behavioural dimensions into the DSS. The main feature of the DSS is the modelling land use type and groundwater extraction and their combined impact on ground water level, ground water stock and the environment. Climate scenarios are also incorporated into the DSS in order to improve the forecast of the ground water level and stock. In summary, DSS methods for assessing and planning the future are necessary to maintain the reliability and sustainability of water resource management in the long term. In addition, the DSS can assist the process of communicating the results with stakeholders, government and the community.

\section{Acknowledgements}

This work was funded by the Gnangara Sustainability Strategy and the CSIRO Water for a Healthy Country Flagship. The authors gratefully acknowledge the considerable advice and assistance from the members of the Gnangara Sustainability Strategy Taskforce. 


\section{References}

[1] Beddek R., A. Elmahdi, B. Barnett and T. Kennedy (2005). 'Integration of Groundwater Models within an Economical Decision Support System Framework'. In Zerger, A. and Argent, R.M. (eds) MODSIM 2005 pp. 608614.ISBN:0-9758400-2-9.

[2] Cockerill K, Tidwell VC, Passell HD and Malczynski LA (2007). COMMENTARY: Cooperative modeling lessons for environmental management. Environmental Practice 9:28-41.

[3] CSIRO (2008). Water availability in the Murray-Darling Basin. A report to the Australian Government from the CSIRO Murray-Darling Basin Sustainable Yields Project. CSIRO, Australia. 67pp.

[4] Elmahdi A, and McFarlane D (2009 in preparation). An Integrated multiagency approach for sustainable groundwater management and land-use change

[5] Elmahdi A, Connor J, Ranjan R, Tapsuwan S and McFarlane D (2009 in preparation). Gnangara Decision Support System: Land use changes System analysis approach for sustainable groundwater management: Gnangara case study.

[6] Elmahdi A, Kheireldin K. and Hamdy A (2006b). GIS and multi-criteria evaluation: Robust tools for integrated water resources management. IWRA 31(4).

[7] Elmahdi A, Malano H, and Khan S (2006a).Using a system dynamics approach to model sustainability indicators for the irrigation systems in Australia. Natural Resource Modeling 19(4):465-481.

[8] Elmahdi, A. Malano H, and Khan, S. (2004). 'A System Dynamic Approach And Irrigation Demand Management Modelling'. Environmental Engineering Research Event 2004 conference 6-9 December 2004.

[9] Elshorbagy, A., and L. Ormsbee, (2005). Object-oriented modelling approach to surface water quality management. Environmental Modelling and software.

[10] Rumbaugh, J., M. Blaha, W. Premerlani, F. Eddy, and W. Lorensen, (1991). Object-oriented modeling and design. Prentice Hall, Englewood Cliffs, NJ.

[11] Simonovic, P. and H. Fahmy, (1999). A new modelling approach for water resources policy analysis, Water Resource. Res. Vol. 35(1), 295-304.

[12] Simonovic, P., H. Fahmy, A. Elshorbagy, (1997). The use of object oriented modeling for water resources planning in Egypt. Water Resources Management Vol.11 (4), 243e261.

[13] Simonovic, P. (2000). Tools for water management: one view of the future, Water International Vol. 25(1), 76-88

[14] Tidwell VC and Brink C (2008). Cooperative modeling: linking science, communication, and ground water planning. Ground Water 46(2):174-182.

[15] Xu C (2008) Modelling of Groundwater levels on the Gnangara mound. Version 2.0 produced by Strategic Issues Planning Infrastructure Planning Branch, Perth, WA 2008. 